\title{
Effect of the critical and operational temperatures on the sensitivity of $\mathrm{MgB}_{2} \mathrm{HEB}$ mixers
}

\author{
Evgenii Novoselov, Stella Bevilacqua, Sergey Cherednichenko, Hiroyuki Shibata and Yasuhiro \\ Tokura
}

\begin{abstract}
We present a study of the noise and the gain of $\mathrm{MgB}_{2}$ hot-electron bolometer mixers with different critical temperatures $\left(T_{c}\right)$ and at various operation temperatures. At a Local Oscillator (LO) frequency of $1.63 \mathrm{THz}$ the minimum input receiver noise temperature $\left(T_{r}\right)$ was $700 \mathrm{~K}$ with a gain of $-18 \mathrm{~dB}$ for a device with a $T_{c}$ of $8.5 \mathrm{~K}$. For a device with a $T_{c}$ of $22.5 \mathrm{~K}$ the corresponding values were $1700 \mathrm{~K}$ and $-19 \mathrm{~dB}$. For the latter device the $T_{r}$ was $2150 \mathrm{~K}$ at a bath temperature of $12 \mathrm{~K}$, which is not achievable with Nb-compound based HEB mixers. We present and compare different methods for measurements of the HEB mixer gain and the output noise.
\end{abstract}

Index Terms-HEB, THz mixer, sub-mm astronomy, bolometer, conversion gain, noise temperature, $\mathbf{M g B}_{2}$.

\section{INTRODUCTION AND BACKGROUND}

$\mathrm{H}$ ot-electron bolometer (HEB) mixers have been proven to be a class of highly sensitive terahertz $(\mathrm{THz})$ detection elements (from $1.3 \mathrm{THz}$ to $5.3 \mathrm{THz}$ ) employed in many receivers for astronomical and atmospheric science observation programs launched in recent years, including RLT [1], APEX [2], [3], Herschel [4], [5], TELIS [6], [7], SOFIA [8], [9]. They are also chosen for different programs under development, such as ASTE [10], DATE5 [11].

Until recently, the state-of-the-art phonon-cooled HEBs were fabricated using either $\mathrm{NbN}$ or $\mathrm{NbTiN}$ superconducting ultrathin films providing a low Double Sideband (DSB) receiver noise temperature $\left(T_{r}\right)$ at Intermediate Frequencies (IF) less than $2 \mathrm{GHz}$ : from $300 \mathrm{~K}$ (corrected for optical losses) at $1.3 \mathrm{THz}$ local oscillator (LO) [11] to $1150 \mathrm{~K}$ (in a vacuum setup) at $5.3 \mathrm{THz}$ LO [12]. It has been shown that at frequencies over $3 \mathrm{THz}$ the quantum noise term starts "to take over" other terms and becomes dominant at higher frequencies [13], [14].

Due to a limited electron temperature relaxation rate in thin $\mathrm{NbN}$ and NbTiN films, HEB mixers have a gain bandwidth

Manuscript received July 2, 2015. This work was supported by the European Research Council (ERC).

E. Novoselov, S. Bevilacqua, S. Cherednichenko, are with the Department of Microtechnology and Nanoscience (MC2), Chalmers University of Technology, SE-41296 Göteborg, Sweden (e-mail: evgenii@chalmers.se).

H. Shibata and Y. Tokura are with NTT Basic Research Laboratories, 3-1 Wakamiya, Morinosato, Atsugi, Kanagawa 243-0198, Japan.
(GBW) $<4 \mathrm{GHz}$. As a result, a $T_{r}$ increases towards higher IFs and doubles already at IF of 4-5GHz. Therefore, the number of scientific tasks in radio astronomy that can be performed with HEB mixers becomes limited. Furthermore, a superconducting critical temperature $\left(T_{c}\right)$ of $8-11 \mathrm{~K}$ limits the $\mathrm{NbN}$ and $\mathrm{NbTiN}$ HEB mixer operation to liquid helium (LHe) temperatures $(\leq 4.2 \mathrm{~K})$. $4 \mathrm{~K}$ cryocoolers qualified for space application are rarae aves, which necessitates utilization of LHe and leads to the reduction of the spaceborn mission lifetime. The discovery of superconductivity in $\mathrm{MgB}_{2}$ [15] with the highest $T_{c}$ among intermetallic compounds (bulk $T_{c}=$ $39 \mathrm{~K}$ ) and recent progress in ultrathin film deposition [16], [17] opened new opportunities in HEB development [18]-[23].

In previously published work there have been two main goals in $\mathrm{MgB}_{2} \mathrm{HEB}$ mixer development: a large GBW and a low $T_{r}$. A GBW of 2-3 GHz was reported both for thicker films with a higher $T_{c}(20 \mathrm{~nm}, 20 \mathrm{~K})$ and for thin films with a much lower $T_{c}(10 \mathrm{~nm}, 9 \mathrm{~K})$ [18], [19]. A possibility of achieving a GBW of $8-10 \mathrm{GHz}$ with HEB mixers made from thin films with a high $T_{c}$ was also suggested in [20], which was recently confirmed in experimental work by Cunnane et al. [22]. In that paper a GBW of $7 \mathrm{GHz}$ (at 9K) and $8 \mathrm{GHz}$ (at $25 \mathrm{~K}$ ) was demonstrated for a device made from a $15 \mathrm{~nm}$ thick $\mathrm{MgB}_{2}$ film with a $T_{c}$ of $33 \mathrm{~K}$. A feasibility of achievement of a low $T_{r}$ was already demonstrated in the first publications on the $\mathrm{MgB}_{2} \mathrm{HEB}$ mixers, which allowed for measurements of the mixer noise bandwidth (NBW), as a more appropriate criterion for the HEB mixer performance assessment. At the moment the state-of-the-art $T_{r}$ for $\mathrm{MgB}_{2}$ devices is $600 \mathrm{~K}$ at a $600 \mathrm{GHz} \mathrm{LO}$ [19], and $1150 \mathrm{~K}$ at a $1.63 \mathrm{THz} \mathrm{LO}$ [21]. Both figures were reported for devices made from $10 \mathrm{~nm}$ films with a $T_{c}$ of $9 \mathrm{~K}$ and a NBW of $3 \mathrm{GHz}$. For devices with a higher $T_{c}$, a higher $T_{r}$ was observed (e.g. $1800 \mathrm{~K}$ in [20]), but a NBW was more superior $(6-7 \mathrm{GHz})$. For the device with a $T_{c}$ of $33 \mathrm{~K}$ a $T_{r}$ of $3900 \mathrm{~K}$ was measured [22].

So far very few studies have been performed to understand how HEB mixers would operate at temperatures higher than LHe or how mixer performance depends on the bath temperature. A low $T_{c}$ for $\mathrm{NbN}$ thin films $(8-10 \mathrm{~K}$ for $3-10 \mathrm{~nm}$ films) does not facilitate studying HEB mixer operation at higher temperatures [24]. However, $\mathrm{MgB}_{2} \mathrm{HEB}$ mixers offer such a possibility. In [20], it was shown at a $600 \mathrm{GHz} \mathrm{LO}$ that for $\mathrm{MgB}_{2} \mathrm{HEB}$ mixers the $T_{r}$ remained constant up to $11 \mathrm{~K}$ ( $T_{c}$ 
$=15 \mathrm{~K})$. However, no further details were provided.

Currently, the highest $T_{c}$ of our $\mathrm{MgB}_{2}$ films is about $22-24 \mathrm{~K}$ for $20 \mathrm{~nm}$. In this paper, we present an experimental investigation and analysis of the noise temperature, the NBW, and the conversion gain at a $1.63 \mathrm{THz} \mathrm{LO}$ with different bath temperatures for devices made from two films with either a $8.5 \mathrm{~K}$ or a $22.5 \mathrm{~K} T_{c}$. We used three methods to obtain the mixer gain, which gave very similar results. Moreover, we present a study of how the most important mixer characteristics, such as the noise temperature and the conversion gain, vary when both the $T_{c}$ and the film thickness alter over a wide range.

\section{DEVICE FABRICATION AND DC CHARACTERIZATION}

Two batches of the HEBs were fabricated using $\mathrm{MgB}_{2}$ films that are $10 \mathrm{~nm}$ and $20 \mathrm{~nm}$ thick. Films were deposited on a ccut sapphire substrate by molecular-beam epitaxy (MBE) and covered in-situ with a $20 \mathrm{~nm}$ gold layer to prevent film degradation and to reduce contact resistance between the $\mathrm{MgB}_{2}$ film and the metal layers deposited later. The HEBs were fabricated using e-beam lithography and argon ion beam milling in several steps. Each substrate held 8 HEBs of various dimensions. For the $20 \mathrm{~nm}$ film all devices survived during the processing and the dicing, but for the $10 \mathrm{~nm}$ film the yield was quite low and only several devices were usable. For radiation coupling into the bolometer, a broadband planar spiral antenna

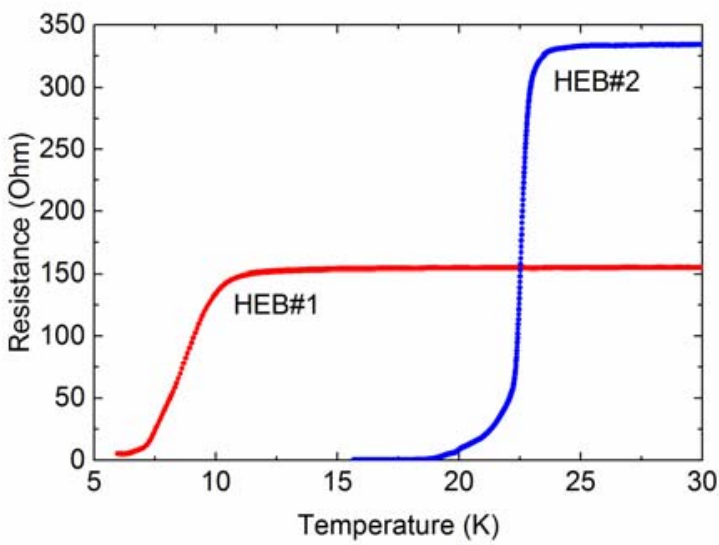

Fig. 1. Resistance versus temperature dependence for the tested devices. TABLE I

$\mathrm{MGB}_{2}$ HEB SIZE $(W \times L)$, THICKNESS $(D)$, CRITICAL TEMPERATURE $\left(T_{C}\right)$, TRANSITION WIDTH $\left(\Delta T_{C}\right)$, RESISTANCE AT 300K $\left(R_{300 K}\right)$, SHEET RESISTANCE $\left(R_{S}\right)$, RESISTIVITY $(P)$, CRITICAL CURRENT AT 4.2K $\left(I_{C}\right)$ AND CRITICAL CURRENT DENSITY $\left(J_{C}\right)$.

\begin{tabular}{|c|c|c|c|c|c|}
\hline \# & $W \mathrm{x} L\left(\mu \mathrm{m}^{2}\right)$ & $D(\mathrm{~nm})$ & $T_{c}(\mathrm{~K})$ & $\Delta T_{c}(\mathrm{~K})$ & $R_{300 K}(\Omega)$ \\
\hline 1 & $1 \times 1$ & 10 & 8.5 & 2.5 & 160 \\
\hline 2 & $1 \times 0.2$ & 20 & 22.5 & 0.6 & 330 \\
\hline \# & $R_{S}(\Omega / \square)$ & $\begin{array}{c}\rho \\
\left(10^{-6} \Omega \mathrm{cm}\right)\end{array}$ & \multicolumn{2}{|c|}{$\begin{array}{c}I_{c}\left(10^{-6} \mathrm{~A}\right) \\
@ 4.2 \mathrm{~K}\end{array}$} & $\begin{array}{c}J_{c} \\
\left(10^{6} \mathrm{~A} / \mathrm{cm}^{2}\right)\end{array}$ \\
\hline 1 & 160 & 160 & \multicolumn{2}{|c|}{70} & 0.7 \\
\hline 2 & 1650 & 3300 & \multicolumn{2}{|c|}{1000} & 5 \\
\hline
\end{tabular}

was made from $270 \mathrm{~nm}$ gold film in the same process. Devices were passivated with a $40 \mathrm{~nm} \mathrm{SiN}_{\mathrm{x}}$ for protection from degradation due to both oxidation and exposure to water [25]. One device from the each batch was chosen for tests. The criteria for device selection were: the small size and low critical current density (to fulfil LO power requirement with the available source), and a DC resistance close to $100 \Omega$ (the designed impedance of spiral antenna). HEB\#1 discussed below, was $10 \mathrm{~nm}$ thick and $1 \times 1 \mu \mathrm{m}^{2}$ in size, with a $T_{c}$ of $8.5 \mathrm{~K}$, a transition width of $2.5 \mathrm{~K}$, and a room temperature resistance of $160 \Omega$. HEB\#2 was $20 \mathrm{~nm}$ thick and $1 \times 0.2 \mu \mathrm{m}^{2}$ in size, with a $T_{c}$ of $22.5 \mathrm{~K}$, a transition width of $0.6 \mathrm{~K}$, and a room temperature resistance of $330 \Omega$. R-T curves measured in a dip-stick for both HEBs are presented in Fig. 1. The presence of the double transition in the R-T curve for HEB\#2 (Fig. 1) suggests that the electrical contact between $\mathrm{MgB}_{2}$ and $\mathrm{Au}$ was quite good.

$\mathrm{I}-\mathrm{V}$ curves of HEB\#1 at $4.2 \mathrm{~K}$ (with and without LO pumping) and the corresponding IF response versus the bias voltage (at a $295 \mathrm{~K}$ load) are presented in Fig. 2. An LO power required to reach the minimum $T_{r}$ (LO3 curve in Fig. 2a) was $70 \mathrm{nW}$ as was calculated using an isothermal method with an assumption that both the direct current (DC) and the LO power have the same effect on the bolometer resistance [26]. The optimal LO power is in the same order of magnitude as that reported for $\mathrm{NbN}$ HEB mixers.

a)

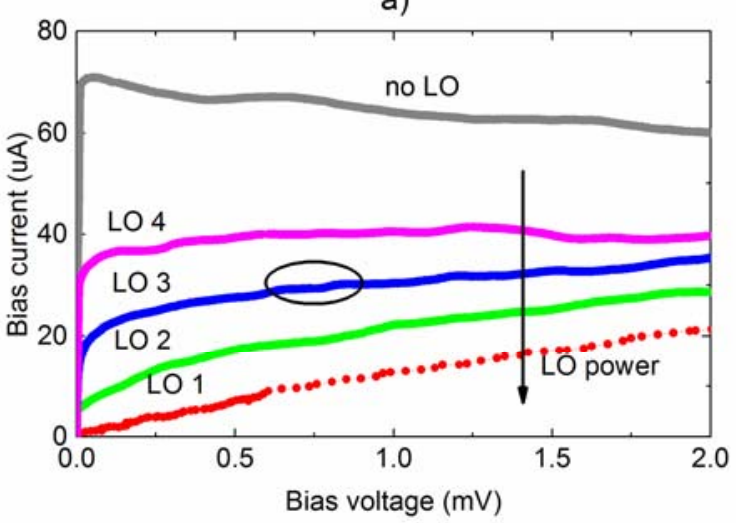

b)

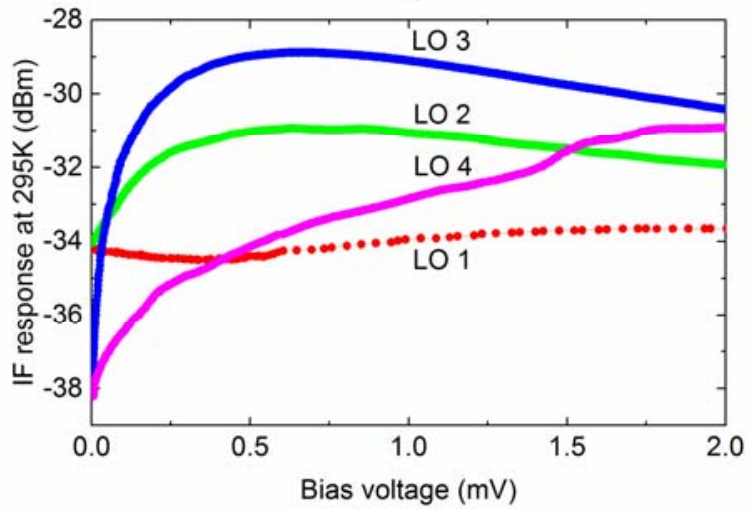

Fig. 2. (a) I-V curves for HEB\#1 under different LO $(1.63 \mathrm{THz})$ power at $4.2 \mathrm{~K}$ bath temperature, optimal operation points marked with a black ellipse and (b) the corresponding IF response at $295 \mathrm{~K}$ load at $1.8 \mathrm{GHz}$ IF. 


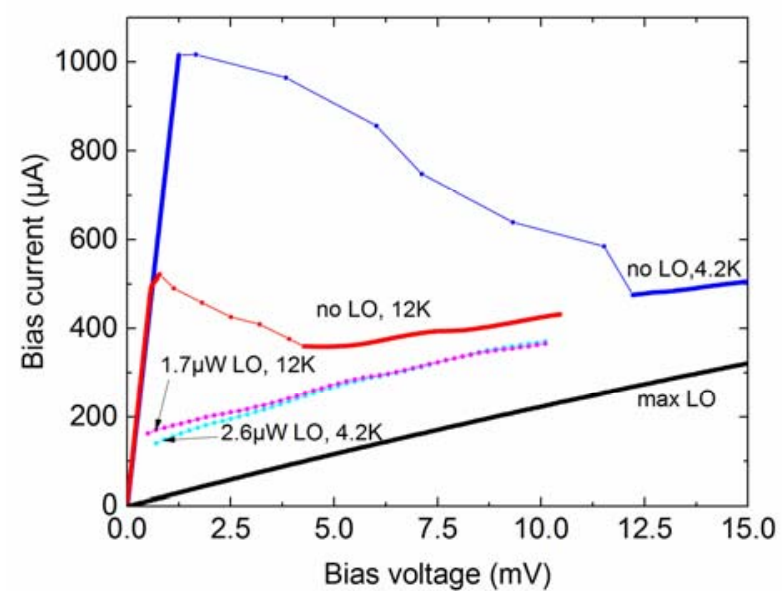

Fig. 3. I-V curves for $\mathrm{HEB} \# 2$ with and without $\mathrm{LO}$ power $(1.63 \mathrm{THz})$ at $12 \mathrm{~K}$ and $4.2 \mathrm{~K}$ bath temperatures.

$\mathrm{I}-\mathrm{V}$ curves of HEB\#2 at $4.2 \mathrm{~K}$ and $12 \mathrm{~K}$ (with and without LO pumping) are presented in Fig. 3. At a bath temperature of about $12 \mathrm{~K}$ the HEB critical current $(0.5 \mathrm{~mA})$ was around half of its value at $4.2 \mathrm{~K}(1 \mathrm{~mA})$. The $\mathrm{LO}$ power calculated using the isothermal method was either $2.6 \mu \mathrm{W}$ for $4.2 \mathrm{~K}$ bath temperature or $1.7 \mu \mathrm{W}$ for $12 \mathrm{~K}$. DC parameters of HEB\#1 and HEB\#2 are summarized in Table I.

\section{MEASUREMEnT SetuP AND EXPERIMENTAL TeChNiQue}

The HEBs were mounted in mixer blocks with Si lenses and placed on the cold plate of a LHe cryostat sealed with a HDPE window. A Zitex ${ }^{\mathrm{TM}}$ IR filter was placed on the $4 \mathrm{~K}$ shield of the cryostat. Losses in the optical path from the hot/cold loads to the mixer and equivalent noise temperatures of the corresponding elements are presented in Table II. Reflection loss of the Si lens $(1 \mathrm{~dB})$ was not included in the list and it was not accounted for. Therefore, for a specific frequency, both the $T_{r}$ and conversion gain can be further reduced/increased by application of a proper designed AR layer for the Si lens [27]. In our case, $\mathrm{Si}$ lens reflection loss was treated as a part of the mixer conversion gain $\left(G_{m}\right)$. A bias-T followed the mixer block to apply the voltage bias to the device and to separate the intermediate frequency (IF) response. Three cascaded amplifiers were used in the IF chain to measure the IF response: a 2-4GHz InP low-noise amplifier mounted on the cryostats' cold plate, a 2-4GHz GaAs low-noise amplifier at TABLE II

LOSSES (L) AND EQUIVALENT NOISE TEMPERATURES ( $\left.\mathrm{T}_{\mathrm{EQ}}\right) \mathrm{OF}$ OPTICAL COMPONENTS ALONG THE BEAM PATH AT 1.63THZ REFERED TO THE INPUT OF THE CORRESPONDING COMPONENT. T IS THE PHYSICAL TEMPERATURE OF THE COMPONENT.

\begin{tabular}{cccc}
\hline \hline Component & $T(\mathrm{~K})$ & $L(\mathrm{~dB})$ & $T_{e q}(\mathrm{~K})$ \\
\hline Air path $(40 \mathrm{~cm})$ & 295 & 1 & 76.4 \\
Beam splitter $\left(\mathrm{Mylar}^{\circledR}\right)$ & 295 & 0.1 & 7.0 \\
Cryostat's window (1 mm HDPE) & 295 & 0.7 & 52.5 \\
IR filter (2 Zitex ${ }^{\mathrm{TM}}$ sheets) & 4.2 & 0.6 & 0.6 \\
\hline Total & - & 2.4 & 137
\end{tabular}

room temperature outside the cryostat, and a broadband (0.1$10 \mathrm{GHz}$ ) amplifier at the end. A $3 \mathrm{~dB}$ attenuator was placed between the cryostat and the first room temperature LNA to reduce standing waves in the long IF cable. The amplified signal was measured through a tunable (1-9 GHz) YIG-filter (50MHz bandwidth) with a power meter. Mylar ${ }^{\circledR}$ beam splitters (BS) (of either $12 \mu \mathrm{m}$ or $3 \mu \mathrm{m}$ thick) were used to combine the LO and the signal (from the hot/cold loads) beams. Noise measurements were performed with a $1.6 \mathrm{THz}$ LO (a far-infrared (FIR) gas laser) at bath temperatures of $4.2 \mathrm{~K}, 2.7 \mathrm{~K}$ (achieved by helium vapour pumping) and $12 \mathrm{~K}$ (achieved by use of a resistive heater mounted on the mixer block). A Golay cell connected to the oscilloscope was placed behind the beam splitter to monitor the FIR gas laser emission power during experiments.

For measurements of the $T_{r}$ the standard Y-factor technique (295K/77K loads) was used. In order to obtain the mixer conversion gain and the mixer output noise temperature, a Ufactor technique was applied as described in [21], [29]. In this case, the receiver conversion gain can be calculated as:

$G_{\text {tot }} \equiv G_{m} / L_{o p t}=\frac{U\left(T_{L N A}+T_{R E F}\right)}{2\left(T_{r e c}+T(295)\right)}$

where $L_{\text {opt }}$ is the optical loss ( $2.4 \mathrm{~dB}$ in our case), $T_{L N A}$ is the IF chain noise temperature. $T_{R E F}$ is the reference temperature that depends on the state chosen as the reference to measure the Ufactor. For the superconducting state $T_{R E F}$ is equal to $T_{L N A}$, because in this state the HEB acts as a microwave short and hence it reflects the power coming from the IF chain. For the normal state, achieved by pumping with all available LO power (e.g. using a mirror instead of a BS), the noise does not depend on the bias point (LO1 curve on Fig. 2) and it is defined by the Johnson noise of the HEB, so $T_{R E F}$ is equal to the HEB electron temperature determined from the R-T curve by DC resistance. The factor " 2 " in the equation comes from the DSB operation of the mixer with an assumption that the sideband ratio is 1 . As follows from (1), the mixer output noise temperature $T_{\text {out }}$ can be calculated as:

$T_{\text {out }}=U\left(T_{L N A}+T_{R E F}\right)-T_{L N A}-2 G_{\text {tot }} T(295 K)-2 G_{\text {tot }} T_{R F}$

where $T_{R F}$ is the noise contribution of optical components (137K in our case, see Table II).

Another method to obtain the mixer conversion gain and the mixer output noise temperature is from the output noise of the HEB mixer $\left(\mathrm{P}_{\mathrm{IF}}\right)$ at the operation point and an accurate measurements of the IF chain gain, $G_{I F}$ :

$G_{\text {tot }}=P_{I F} / 2 G_{I F} k_{B} B\left(T_{\text {rec }}+T(295)\right)$

$T_{\text {out }}=P_{I F} / 2 G_{I F} k_{B} B-T_{L N A}-2 G_{\text {tot }} T(295 K)-2 G_{\text {tot }} T_{R F}$

where $k_{B}$ is Boltzmann constant, and $B$ is the bandwidth of the IF filter (see above in this Section).

\section{EXPERIMENTAL RESULTS AND DISCUSSION}

For HEB\#1, the $T_{r}$ (corrected for optical losses, as in Table II) versus the intermediate frequency at the $4.2 \mathrm{~K}$ bath temperature is presented in Fig. 4 (circles).

Equation (5) is usually used to define the receiver NBW [28]: 


$$
T_{m}=T_{m}(0)\left[1+\left(f_{I F} / f_{N}\right)^{2}\right\rfloor
$$

where $T_{m}(0)$ is the noise temperature at zero IF, and $f_{N}$ is the NBW. Fitting the measured $T_{r}$ for HEB\#1 to (5), both $T_{m}(0)$ of $1150 \mathrm{~K}$ and $\mathrm{f}_{\mathrm{N}}$ of $3.5 \mathrm{GHz}$ were obtained.

The $T_{r}$ was also measured at a bath temperature of $2.7 \mathrm{~K}$. This resulted in a 30\% increase in the HEB critical current $(90 \mu \mathrm{A})$ and a $40 \%$ reduction of the $T_{r}$ (Fig. 4). The optimal operation region moved to slightly higher bias voltages. The required $\mathrm{LO}$ power calculated with the isothermal method was $80 \mathrm{nW}$. The $T_{r}$ corrected for optical losses versus the IF for the optimal operation point at $2.7 \mathrm{~K}$ is presented in Fig. 4 (diamonds). Experimental points are fitted to (5) as was done for the data obtained at $4.2 \mathrm{~K}$. It provides the zero IF noise temperature of $700 \mathrm{~K}$ and the NBW of $3.2 \mathrm{GHz}$.

The mixer conversion gain and the mixer output noise temperature were calculated as discussed in Section III using experimental data from Fig. 4 and Fig. 2b. The noise temperature of the IF chain is determined mostly by the noise temperature of the first amplifier in the chain i.e. by the cold LNA, which is mounted on the cryostat's $4.2 \mathrm{~K}$ plate. It has a gain of $30 \mathrm{~dB}$ and a noise temperature of $2 \mathrm{~K}$. Therefore, the noise temperature of the whole IF chain was estimated as not to exceed $3 \mathrm{~K}$. The total gain of the entire IF chain, $G_{I F}$ was measured to be $77 \mathrm{~dB}$ at $1.8 \mathrm{GHz}$. Using an IF response at the optimal operation point $\left(U_{0}=0.8 \mathrm{mV}\right.$ and $\left.I_{0}=28 \mu \mathrm{A}\right)$ of $29.4 \mathrm{dBm}$, a U-factor of either $8.2 \mathrm{~dB}$ (reference state is the superconducting state) or $4.7 \mathrm{~dB}$ (reference state is the normal state), the $T_{r}=2500 \mathrm{~K}$, and the HEB temperature of $T_{R E F}=9 \mathrm{~K}$ in the normal state, both the mixer conversion gain and the mixer output noise temperature were calculated at $4.2 \mathrm{~K}$ with all three methods presented in Section III.

At $2.7 \mathrm{~K}$, the input data for the calculation of the mixer conversion gain and the mixer output noise temperature (at an operation point of $U_{0}=1.3 \mathrm{mV}$ and $I_{0}=23 \mu \mathrm{A}$ ) for HEB\#1 were: the IF response $P_{I F}=-30.4 \mathrm{dBm}$, the $\mathrm{U}$-factor was either $7.2 \mathrm{~dB}$ (reference state is the superconducting state) or $4.2 \mathrm{~dB}$ (reference state is the normal state), the $T_{r}=1500 \mathrm{~K}$, and the HEB temperature $T_{R E F}=9.3 \mathrm{~K}$.

As one can see from TABLE III the mixer conversion gain and the mixer output noise temperature obtained using three methods are quite close to each other, which we interpret as a confirmation that the methods are correct. As the mixer temperature is reduced from $4.2 \mathrm{~K}$ to $2.7 \mathrm{~K}$, the mixer

TABLE III

THE MIXER CONVERSION GAIN $\left(G_{m}\right)$ AND THE OUTPUT NOISE TEMPERATURE $\left(T_{\text {out }}\right)$ FOR HEB\#1 CALCULATED: USING (1) AND (2) EITHER WITH THE SUPERCONDUCTING (i) OR THE NORMAL (ii) STATES AS THE REFERENCE STATE; USING (3) AND (4) (iii). MEASUREMENTS WERE PERFORMED BOTH AT $4.2 \mathrm{~K}$ AND $2.7 \mathrm{~K}$ BATH TEMPERATURES $\left(T_{\text {bath }}\right) . f_{I F}=1.8 \mathrm{GHz}$.

\begin{tabular}{ccccccc}
\hline & \multicolumn{3}{c}{$\mathrm{i}$} & \multicolumn{2}{c}{ ii } \\
\hline $\begin{array}{c}T_{\text {bath }} \\
(\mathrm{K})\end{array}$ & $\begin{array}{c}G_{m} \\
(\mathrm{~dB})\end{array}$ & $\begin{array}{c}T_{\text {out }} \\
(\mathrm{K})\end{array}$ & $\begin{array}{c}G_{m} \\
(\mathrm{~dB})\end{array}$ & $\begin{array}{c}T_{\text {out }} \\
(\mathrm{K})\end{array}$ & $\begin{array}{c}\mathrm{G}_{\mathrm{m}} \\
(\mathrm{dB})\end{array}$ & $\begin{array}{c}T_{\text {out }} \\
(\mathrm{K})\end{array}$ \\
\hline 4.2 & -19.1 & 31 & -19.6 & 27 & -19.9 & 26 \\
2.7 & -18.2 & 21 & -18.1 & 22 & -18.9 & 18
\end{tabular}

conversion gain is increased by approximately $1 \mathrm{~dB}$, whereas the output mixer noise temperature is decreased by $5-10 \mathrm{~K}$. It is of interest to compare these experimental data with physical modelling of the devices, however this will be a subject for a further publication. It is also interesting to compare results of HEB\#1 with published data for NbN HEB mixers, since a $T_{c}$ of $\mathrm{NbN}$ thin films $(8-10 \mathrm{~K})$ is very close to the $T_{c}$ of the $\mathrm{MgB}_{2}$ film used for HEB\#1. The reported conversion gain of $\mathrm{NbN}$ HEBs is approximately $-12 \mathrm{~dB}$ [29] with the mixer output noise temperature of approximately $40 \mathrm{~K}$ at a $1.63 \mathrm{THz} \mathrm{LO}$. A lower gain and a lower output noise for the $\mathrm{MgB}_{2} \mathrm{HEB}$ mixer (HEB \#1) can be a result of a quite large superconducting transition width (see Fig. 1). The GBW of $\mathrm{MgB}_{2} \mathrm{HEB}$ [20] also shows to be a factor of 1.5 smaller, as compared to the $\mathrm{NbN}$ HEB mixer from [28]. Therefore, for comparison of the gain and the output noise at $1.8 \mathrm{GHz}$ (approximately the $3 \mathrm{~dB}$ gain roll-off frequency for HEB\#1) about a $+2 \mathrm{~dB}$ correction has to be applied for the $\mathrm{MgB}_{2}$ mixer. Despite this, the $T_{r}$ for both $\mathrm{NbN}$ and $\mathrm{MgB}_{2} \mathrm{HEB}$ mixers falls within the same ball park.

HEB\#2 was tested using the same setup, except that it was mounted in a mixer block with a $5 \mathrm{~mm}$ Si lens. The measured $T_{r}$ spectrum across the $1-4 \mathrm{GHz}$ IF band for the bath temperature of $4.2 \mathrm{~K}$ and a fit with (5) are presented in Fig. 5. At certain IFs the mixer response to the hot/cold loads was unstable which resulted in errors in the noise temperature measurements (e.g. at $1.9 \mathrm{GHz}$ and $2.9 \mathrm{GHz}$ ). The fitted line corresponds to the zero IF noise temperature of $1700 \mathrm{~K}$ and the NBW of $5 \mathrm{GHz}$.

The mixer conversion gain and the mixer output noise temperature were calculated using the U-factor technique with the normal state as a reference state. Results are shown in Fig. 6 . Higher ripples for IF $<1.8 \mathrm{GHz}$ correspond to the IFs with a high LNA return loss. The mixer conversion gain was fitted with a single-pole Lorentzian $G_{m}\left(f_{I F}\right)=G_{m}(0) /\left[1+\left(f_{I F} / f_{g}\right)^{2}\right]$, where $G_{m}(0)$ is the mixer conversion gain at zero IF and $f_{g}$ is the mixer GBW ( $3 \mathrm{~dB}$ gain roll-off frequency). The fit in Fig. 6a corresponds to the zero IF mixer gain of $-15.1 \mathrm{~dB}$ and a GBW of $3.5 \mathrm{GHz}$. The same noise and gain measurements as

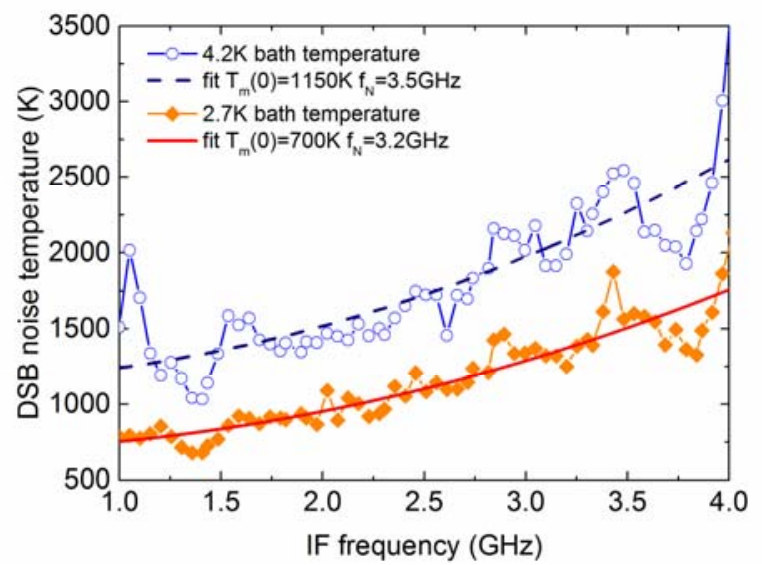

Fig. 4. The DSB receiver noise temperatures (corrected for optical losses) for the HEB\#1. The bias points are $U_{0}=0.8 \mathrm{mV} I_{0}=28 \mu \mathrm{A}$ and $U_{0}$ $=1.3 \mathrm{mV} I_{0}=23 \mu \mathrm{A}$ at $4.2 \mathrm{~K}$ and $2.7 \mathrm{~K}$ bath temperatures, respectively. 


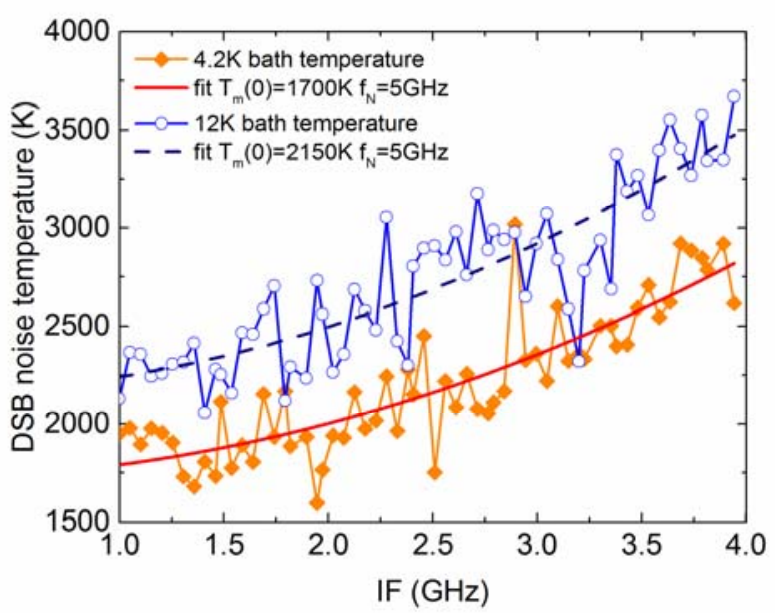

Fig. 5. The DSB receiver noise temperatures (corrected for optical losses) at $4.2 \mathrm{~K}$ (diamonds) and $12 \mathrm{~K}$ (circles) bath temperatures at a $1.63 \mathrm{THz}$ LO for HEB\#2. The bias points are $U_{0}=1.8 \mathrm{mV} I_{0}=200 \mu \mathrm{A}$ and $U_{0}=1.6 \mathrm{mV} I_{0}=180 \mu \mathrm{A}$, respectively.
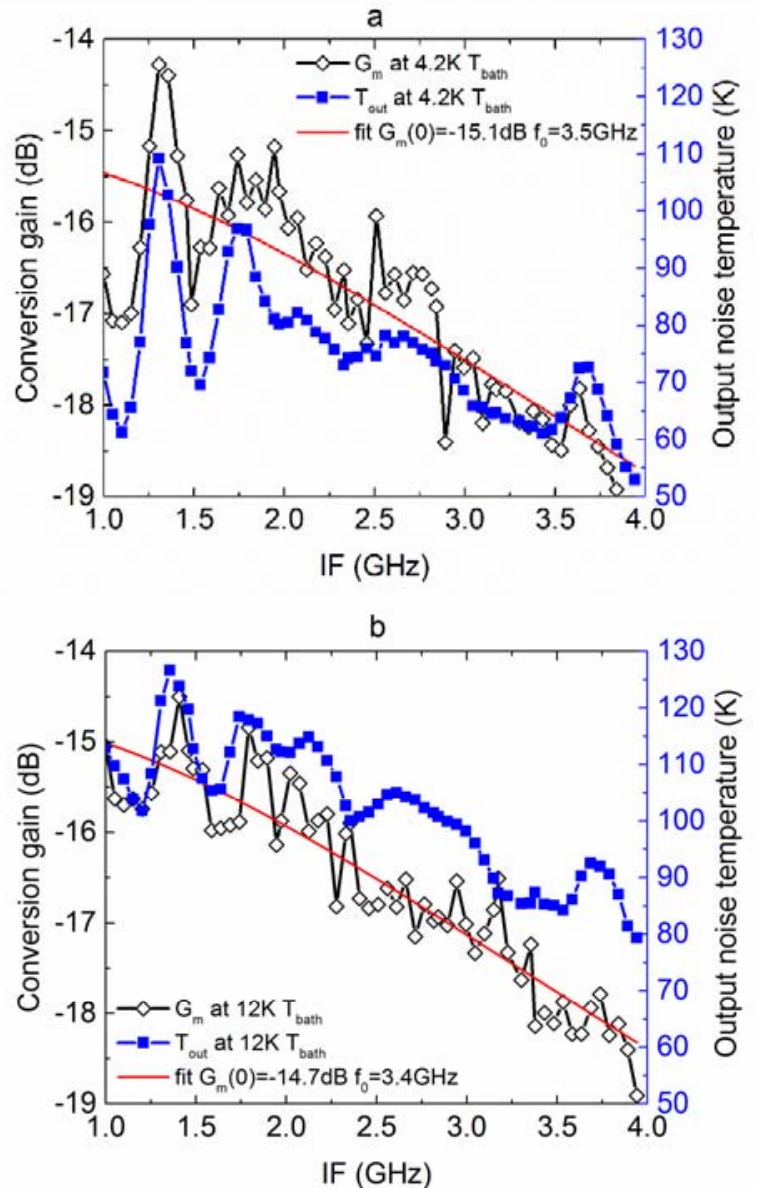

Fig. 6. The measured mixer gain (open diamonds) and output mixer noise temperature (squares) of $\mathrm{HEB} \# 2$ versus IF at a $1.63 \mathrm{THz} \mathrm{LO}$ at (a) $4.2 \mathrm{~K}, U_{0}=1.6 \mathrm{mV}_{0}=180 \mathrm{uA}$ and (b) $12 \mathrm{~K}, U_{0}=1.8 \mathrm{mV}, I_{0}=200 \mu \mathrm{A}$.

at $4.2 \mathrm{~K}$ were conducted at $12 \mathrm{~K}$. Results are shown in Fig. 5 and Fig. 6 . The fitted zero IF noise temperature, the NBW, the mixer conversion gain and the GBW are $2150 \mathrm{~K}, 5 \mathrm{GHz}$, $14.7 \mathrm{~dB}$ and $3.4 \mathrm{GHz}$, respectively. These data show that both the conversion gain and the GBW stays almost the same at both bath temperatures, but the output noise at a higher bath
TABLE IV

THE DSB RECEIVER NOISE TEMPERATURE $\left(\mathrm{T}_{\mathrm{R}}\right)$, THE NOISE BANDWIDTH $\left(\mathrm{F}_{\mathrm{N}}\right)$, THE MIXER CONVERSION GAIN $\left(\mathrm{G}_{\mathrm{M}}\right)$, THE GAIN BANDWIDTH $\left(\mathrm{F}_{\mathrm{G}}\right)$ AND THE OUTPUT MIXER NOISE TEMPERATURE (Tout) FOR MIXERS HEB\#1, HEB\#2 AND NBN HEB MIXER[29]

\begin{tabular}{|c|c|c|c|c|c|}
\hline & \multicolumn{2}{|c|}{$H E B \# 1$} & \multicolumn{2}{|c|}{$H E B \# 2$} & \multirow{2}{*}{$\begin{array}{c}N b N \\
H E B[29] \\
@ 4.2 K\end{array}$} \\
\hline & @ $2.7 K$ & (a) $4.2 \mathrm{~K}$ & @4.2K & @12K & \\
\hline $\mathrm{T}_{\mathrm{r}}, \mathrm{K}$ & 700 & 1150 & 1700 & 2150 & 800 \\
\hline $\mathrm{f}_{\mathrm{N}}, \mathrm{GHz}$ & 3.2 & 3.5 & 5 & 5 & - \\
\hline $\mathrm{G}_{\mathrm{m}}, \mathrm{dB}$ & -18 & -19 & -15 & -15 & -12.3 \\
\hline $\mathrm{f}_{\mathrm{g}}, \mathrm{GHz}$ & - & - & 3.5 & 3.4 & - \\
\hline $\mathrm{T}_{\text {out }}, \mathrm{K}$ & 22 & 27 & 80 & 115 & 40 \\
\hline
\end{tabular}

temperature is higher, similar to the behaviour observed for the "low" $T_{c}$ HEB mixer, which results in a higher $T_{r}$. The acquired parameters of both HEBs are summarised in Table IV together with values for an NbN HEB mixer [29] for comparison.

Two tested HEB mixers differed, not only in terms of the critical temperature, but also $\mathrm{MgB}_{2}$ film thickness. As it follows from the HEB mixer theory, and some experiments with NbTiN HEB mixers [10], the film thickness affects the GBW and NBW of the device due to a longer phonon escape time. However, it should not affect the noise temperature (at IF $<<$ GBW) unduly. Our experimental data shows that this is also the case for $\mathrm{MgB}_{2} \mathrm{HEB}$ mixers.

\section{CONCLUSION}

This study shows that for superconducting films with a higher $T_{c}$ both the output noise temperature and the conversion gain of HEB mixers increase as compared to the films with a lower $T_{c}$. This is valid for the optimal operation conditions. At the same time films with a higher $T_{c}$ provide a broader NBW, as has been discussed in previous works. Already having reached a $T_{c}$ of $22 \mathrm{~K}$, the HEB mixer can operate above $12 \mathrm{~K}$ with only a $25 \%$ increase of the receiver noise temperature, compared to that at $4.2 \mathrm{~K}$. Achieving the HEB mixers with a $T_{c}$ $>30-35 \mathrm{~K}$ will push the HEB operation temperature above $20 \mathrm{~K}$ with no or very small sensitivity reduction. In addition, we have demonstrated that the quality of $\mathrm{MgB}_{2}$ is not critically important to achieving low noise temperature in the $2-4 \mathrm{~K}$ temperature range and $\mathrm{IF}<2 \mathrm{GHz}$.

In this work we achieved a mixer noise temperature and a noise bandwidth comparable to $\mathrm{NbN}$ HEBs using quite low quality $\mathrm{MgB}_{2}$ thin films with a "low" $T_{c}$ (compared to a $T_{c}$ of $39 \mathrm{~K}$ for the bulk $\mathrm{MgB}_{2}$ or $33-38 \mathrm{~K}$ for the high quality $\mathrm{MgB}_{2}$ films). The required LO power in this case is approximately $100 \mathrm{nW}$, which can be easily realized with the available source technologies for frequencies, even above 2THz. Fabricated devices demonstrated high robustness and did not lose their properties after 1.5 years of storage in a nitrogen atmosphere. However, more specific tests would be required for space application.

Three different methods were applied to estimate the mixer 
conversion gain of the same HEB mixer. Good agreement with an error margin of $\pm 0.5 \mathrm{~dB}$ (which is within the accuracy of these measurements) between methods, indicates that the obtained mixer gain values are correct.

\section{REFERENCES}

[1] D.P. Marrone et al., "Observations in the 1.3 and 1.5 THz Atmospheric Windows with the Receiver Lab Telescope," in Proc. 16th Int. Symp. Space Terahertz Technology, Gothenburg, ISSTT 2005, pp. 64-67.

[2] D. Meledin et al., "A $1.3 \mathrm{THz}$ Balanced Waveguide HEB Mixer for the APEX Telescope," IEEE Trans. Microwave Theory and Tech., vol. 57 pp. 89-98, Jan. 2009.

[3] C. Risacher et al., "First 1.3 THz Observations at the APEX Telescope," in Proc. 20th Int. Symp. Space Terahertz Technology, Charlottesville, ISSTT 2009, pp. 54-61.

[4] Th. de Graauw et al., "The Herschel-Heterodyne Instrument for the FarInfrared (HIFI)," Astron. Astrophys., vol. 518, p. L6, Jul.-Aug. 2010.

[5] P.F. Goldsmith and D.C. Lis, "Early Science Results From the Heterodyne Instrument for the Far Infrared (HIFI) on the Herschel Space Observatory," IEEE Trans. THz Sci. Technol., vol. 2, pp. 383-392, Jul. 2012.

[6] N. Suttiwong et al., "Development and Characterization of the Balloon Borne Instrument Telis (TErahertz and Submm Limb Sounder): 1.8 THz Receiver," in Proc. 19th ESA Symp. European Rocket and Balloon Programmes and Related Research, Bad Reichenhall, PAC 2009, pp. 165-168.

[7] M. Birk et al., "TELIS: TErahertz and subMMW LImb Sounder Project Summary After First Successful Flight," in Proc. 21th Int. Symp. Space Terahertz Technology, Oxford, ISSTT 2010, pp. 195-200.

[8] S. Heyminck et al., "GREAT: The SOFIA high-frequency heterodyne instrument," Astron. Astrophys, vol. 542, p. L1, Jun. 2012

[9] D. Buchel et al., "4.7-THz Superconducting Hot Electron Bolometer Waveguide Mixer," IEEE Trans. THz Sci. Technol., vol. 5, pp.207 214, Mar. 2015

[10] L. Jiang et al., "Development of $1.5 \mathrm{THz}$ waveguide NbTiN superconducting hot electron bolometer mixers," Supercond. Sci. Technol., vol. 23, no. 4, p. 045025, Apr. 2010.

[11] K.M. Zhou et al., "A 1.4 THz quasi-optical NbN superconducting HEB mixer developed for the DATE5 telescope," IEEE Trans. Appl. Supercond., vol. 25, p. 2300805, Jun. 2015.

[12] W. Zhang et al., "Noise temperature and beam pattern of an $\mathrm{NbN}$ hot electron bolometer mixer at 5.25 THz," J. Appl. Phys., vol. 108, no. 9, p. 093102, Nov. 2010.

[13] E. L. Kollberg and K. S. Yngvesson, "Quantum-Noise Theory for Terahertz Hot Electron Bolometer Mixers," IEEE Trans. Microwave Theory and Tech., vol. 54, pp. 2077-2089, May 2006.

[14] W. Zhang et al., "Quantum noise in a terahertz hot electron bolometer mixer," Appl. Phys. Lett., vol. 96, no. 11, pp. 111113, Nov. 2010.

[15] J. Nagamatsu et al., "Superconductivity at $39 \mathrm{~K}$ in magnesium diboride," Nature, vol. 410, no. 6824, pp. 63-64, Feb 2001.

[16] H. Shibata et al., "Ultrathin $\mathrm{MgB}_{2}$ films fabricated by molecular beam epitaxy and rapid annealing," Supercond. Sci. Technol., vol. 26, no. 3, Mar. 2013.

[17] Y. Zhang et al., "Ultrathin $\mathrm{MgB}_{2}$ films fabricated on $\mathrm{Al}_{2} \mathrm{O}_{3}$ substrate by hybrid physical-chemical vapor deposition with high Tc and Jc", Supercond. Sci. Tech., vol. 24, no. 1, 2011.

[18] S. Cherednichenko et al., "Terahertz mixing in $\mathrm{MgB}_{2}$ microbolometers," Appl. Phys. Lett., vol. 90, no. 2, pp. 023507-3, Jan. 2007.

[19] S. Bevilacqua et al., "Low noise $\mathrm{MgB}_{2}$ terahertz hot-electron bolometer mixers," Appl. Phys. Lett., vol. 100, no. 3, p. 033504, Jan. 2012.

[20] S. Bevilacqua et al., "Study of IF Bandwidth of $\mathrm{MgB}_{2}$ Phonon-Cooled Hot-Electron Bolometer Mixers," IEEE Trans. THz Sci. Technol., vol. 3 , pp. 409-415, Jul. 2013

[21] S. Bevilacqua et al., "MgB 2 Hot-Electron Bolometer Mixers at Terahertz Frequencies," IEEE Trans. Appl. Supercond., vol. 25, p. 2301104, Jun. 2015 .

[22] D. Cunnane et al., "Development of hot-electron $\mathrm{THz}$ bolometric mixers using $\mathrm{MgB}_{2}$ thin films," Proc. SPIE, vol. 9153, 91531Q-1, Jul. 2014.

[23] D. Cunnane et al., "Characterization of $\mathrm{MgB}_{2}$ Superconducting Hot Electron Bolometers," IEEE Trans. Appl. Supercond., vol. 25, p. 2300206, Jun. 2015.
[24] S. Cherednichenko et al., "Local oscillator power requirement and saturation effects in NbN HEB mixers," in Proc. 12th Int. Symp. Space Terahertz Technology, San Diego, ISSTT 2001, pp. 273-285.

[25] H.Y. Zhai et al., "Degradation of superconducting properties in $\mathrm{MgB}_{2}$ films by exposure to water," Supercond. Sci. Tech., vol. 14, no. 7, pp. 425-428, Jul. 2001.

[26] B.S. Karasik, "Optimal choice of material for HEB superconducting mixers," IEEE Trans. Appl. Supercond., vol. 9, pp. 4213-4216, Jun. 1999.

[27] A. J. Gatesman et al., "An Anti-Reflection Coating for Silicon Optics at Terahertz Frequencies," IEEE Microwave and guided wave lett., vol. 10, pp. 264-266, Jul. 2000.

[28] S. Cherednichenko et al., "Terahertz superconducting hot-electron bolometer mixers," Physica C, vol. 372-376, no. 1, pp. 407-415, Aug. 2002.

[29] S. Cherednichenko et al., "1.6THz heterodyne receiver for the far infrared space telescope," Physica C, vol. 372-376, no. 1, pp. 427-431, Aug. 2002.

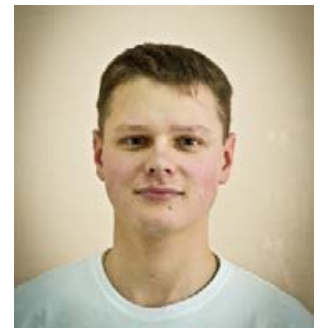

Evgenii Novoselov, was born in 1988 in SaintPetersburg, Russia. He received his B.Sc. and M.Sc. (summs cum laude) in 2009 and 2011, respectively, from The Saint-Petersburg National Research University of Information Technologies, Mechanics and Optics (NRU ITMO).

During his studies at the university, he worked at the research center "Femtosecond optics and femtotechnology" (NRU ITMO) (2007-2011). There he participated in a number of projects on the development of terahertz spectrography and reflectometry using TDS. After compliting his master degree, he joined LLC "TELROS Integration" (Saint-Petersburg, Russia) as a communication systems design engineer (2011-2013). Currently, he is a PhD student at the Terahertz Millimeter Wave Laboratory at Chalmers University of Technology, working on $\mathrm{MgB}_{2}$ Hot Electron Bolometers.

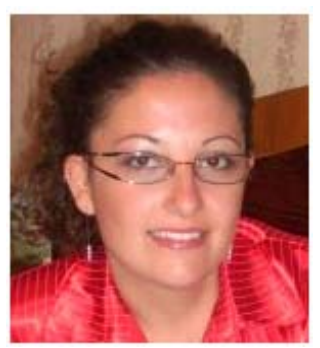

Stella Bevilacqua, was born in 1981 in Pizza Armerina, Italy. She received B.Sc. degree in Electronic Engineering from the University of Catania, Italy, in 2006.

During a four months period, she has done her thesis work in the Smart-Card group of the MPG division of Catania STMicroelectronics. In April 2010, she received her M.Sc. degree in Microelectronic Engineering from the University of Catania with the master thesis: "Fabrication and Characterization of Graphene field-effect transistors (GFETs)." She has received the $\mathrm{PhD}$ degree at Chalmers University of Technology in the Department of Microtechnology and Nanoscience in 2014. Currently, she is a PostDoc at the department of Terahertz Millimeter Wave Laboratory at Chalmers University of Technology, working on $\mathrm{MgB}_{2}$ Hot Electron Bolometers.

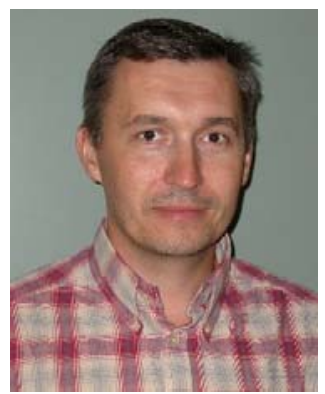

Sergey Cherednichenko, was born in 1970 in Mariupol, Ukraine. He received his Diploma with Honours in Physics in 1993 from Taganrog State Pedagogical Institute, and Ph.D. in physics in 1999 from Moscow State Pedagogical University.

$\mathrm{He}$ is working at the Department of Microtechnology and Nanoscience at Chalmers University of Technology (Gothenburg, Sweden). From 2000-2006 he was involved in development of terahertz band superconducting mixers for the Herschel Space Observatory; and from 2008 till 2009 in the water vapour radiometer for ALMA. As from 2007 he has been an Associate Professor at the department of Microtechnology and Nanoscience at Chalmers University of Technology. His research interests include terahertz heterodyne receivers and mixers, photon detectors; $\mathrm{THz}$ antennas and optics; thin superconducting films and their application for $\mathrm{THz}$ and photonics; and material properties at $\mathrm{THz}$ frequencies. 


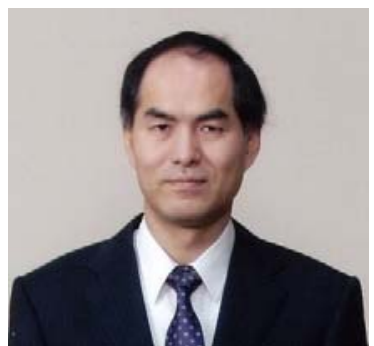

Hiroyuki Shibata received his B.S., M.S., and Ph.D. degrees in physics from Waseda University, Tokyo, in 1985, 1987, and 1997, respectively. In 1987, he joined NTT Basic Research Laboratories, where he has been working on the physics, material development, and device fabrication of superconductors. $\mathrm{He}$ is currently a senior research scientist at NTT Basic Research Laboratories. He has been a guest professor at Osaka University since 2008. Shibata is a member of the Physical Society of Japan, the Japan Society of Applied Physics, and the Institute of Electronics, Information and Communication Engineers.

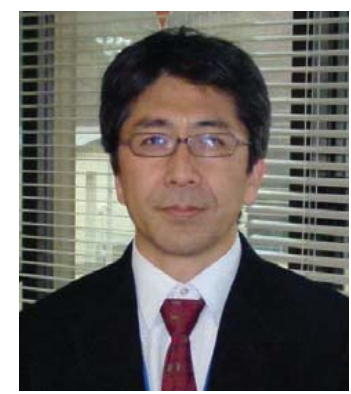

Yasuhiro Tokura received his B.S., M.S., and $\mathrm{Ph} . \mathrm{D}$. degrees from the University of Tokyo in 1983, 1985, and 1998, respectively. In 1985, he joined NTT Musashino Electrical Communications Laboratories, Japan. $\mathrm{He}$ is currently a research professor of NTT Basic Research Laboratories and a professor at the University of Tsukuba. His current research concenrns the theory of quantum transport and non-equilibrium dynamics in semiconductor nano/meso-structures. Tokura is a member of the Physical Society of Japan and the Japan Society of Applied Physics. 